\title{
Electrocatalytic Nitrite Determination Using Iron Phthalocyanine Modified Gold Nanoparticles
}

\author{
Ayman Ali Saeed, ${ }^{[a]}$ Baljit Singh, ${ }^{[b]}$ Mohammed Nooredeen Abbas, ${ }^{[a]}$ Yousry Moustafa Issa,,${ }^{[c]}$ and \\ Eithne Dempsey*[b]
}

\begin{abstract}
Electrochemical detection of nitrite was achieved via electrodeposition of gold nanoparticles (AuNPs) onto glassy carbon electrodes, followed by 3mercaptopropionic acid (MPA) self-assembly, enabling attachment of an iron(III) monoamino-phthalocyanine (FeMAPc) catalyst via amide bond formation. The use of scanning electron microscopy, energy dispersive X-ray spectroscopy and ultraviolet-visible spectroscopy realised surface characterisation while cyclic voltammetry and electrochemical impedance spectroscopy techniques were applied for electrochemical interrogation. The electrochemical behaviour of nitrite at the bare (GCE), AuNPs/ GCE, FeMAPc/GCE and FeMAPc-MPA/AuNPs/GCE
\end{abstract}

was further scrutinised using differential pulse voltammetry in phosphate buffer solution (0.1 M PBS, pH 5.8). Overall the FeMAPc-MPA/AuNPs/GCE resulted in sensitivity $14.5 \mathrm{nA} / \mu \mathrm{M}$, which was double that of AuNPs/GCE, 2.4 times FeMAPc/GCE and 3.5 times the response at a bare GCE, with linear range $1.9 \mu \mathrm{M}-2.04 \mathrm{mM}$ (PBS, $\mathrm{pH}$ 5.8) and LOD $0.21 \mu \mathrm{M}$. An interference study revealed that the proposed sensor (FeMAPc-MPA/AuNPs/ GCE) exhibited a selective response in the presence of interfering anions and the analytical capability of the sensor was demonstrated via nitrite ion determination in real water samples.

Keywords: Nanoparticles $\cdot$ Nitrite detection $\cdot$ Iron phthalocyanine $\cdot$ Self-assembled monolayer

\section{Introduction}

Nitrite is well recognised as a serious environmental pollutant and has widespread use as food additive or preservative, fertilizing agent and corrosion inhibitor [1,2]. In terms of human health impact it can promote the irreversible oxidation of hemoglobin to methemoglobin and hence can reduce the blood's capacity to transport $\mathrm{O}_{2}$, and is known to interact with amines and amides within environmental, food and physiological systems to form highly carcinogenic $\mathrm{N}$-nitrosamine compounds [3-5]. According to the World Health Organisation (WHO), the maximum permissible amount of nitrite ion in drinking water is $3 \mathrm{mg} \mathrm{L}^{-1}$ [6], while the European Community has indicated that the maximum limit is $0.1 \mathrm{mg} \mathrm{L}^{-1}-$ considerably lower [7].

As a result, accurate and rapid determination of nitrite in drinking water, food and environmental samples has attracted much research attention and has involved spectrophotometry [8], solid phase spectrophotometry [9] chromatography [10], chemiluminescence,[11] capillary electrophoresis [12], spectrofluorimetry [13] and electrochemical biosensors [14]. The conventional spectrophotometric determination of nitrite ion is based on the absorbance at $(526 \mathrm{~nm})$ of an azo dye which is formed by the reaction of nitrite with sulfonamide and N-(1-napthyl) ethylene diamine. However, this method has limitations e.g. control of $\mathrm{pH}$, toxicity of reagents, interferents and the time involved for assay. Chromatographic methods also exhibit several disadvantages including the requirement for trained personnel and derivatisation steps. On the other hand, electrochemical techniques can provide simple and cost-effective alternatives for selective and sensitive nitrite determination $[15,16]$, providing a relatively safer and environmentally friendly approach with fewer reagents involved. These are mainly based on potentiometric [17], voltammetric [16] and amperometric [18] measurements. Although the nitrite ion is electroactive at carbon electrodes, its oxidation requires a high overvoltage where oxidisable compounds may interfere [19], hence catalytic modification of the electrode surface is required to lower this value. It has been well-documented in the literature that electrodes modified with metallophthalocyanine and metalloporphyrin complexes can be used as electrocatalysts [20,21].

The selection of such complexes is based on changes in oxidation states while retaining stability and molecular

\section{[a] A. A. Saeed, M. N. Abbas}

Anal. Lab., Applied Organic Chemistry Department,

Chemical Industries Division, National Research Centre Dokki, Cairo, Egypt

[b] B. Singh, E. Dempsey

Centre for Research in Electroanalytical Technologies (CREATE), Institute of Technology Tallaght (ITT Dublin) Tallaght, Dublin 24, Ireland

*e-mail: Eithne.Dempsey@ittdublin.ie

[c] Y. M. Issa

Chemistry Department, Faculty of Science, Cairo University Giza, Egypt 
structure during electrocatalysis. The central metal coordinated to the $\mathrm{N}_{4}$ ring plays the main role in the electrocatalytic process and modification of the ring by attaching different substituents and/or varying the nature of the central metal ion can result in dramatic changes in redox properties and subsequent generation of catalytic currents [22]. Catalytic activity had been observed mainly for those metallophthalocyanine complexes containing electrochemically active central metals such as Fe, Co, Mn and $\mathrm{Cu}$ [23]. Hwang et al. demonstrated that FePc adsorbed on the edge plane of Pyrolytic Graphite was an efficient catalyst for nitrite detection [24]. The electrochemical oxidation of nitrite using co-deposited Pt nanoparticles and Fe(III) on glassy carbon electrode (GCE) has been reported [25].

Electrode modification has involved strategies such as drop casting [18], electropolymerization [26], adsorption on $\mathrm{SiO}_{2} / \mathrm{SnO}_{2} /$ phosphate modified electrode [27] and layer by layer approaches [15]. It is also well known that self-assembly is a suitable method for the preparation of ordered layers onto the electrode surface [28] and self-assembly of AuNPs can be achieved via suitable functional groups including thiol and amine $[29,30]$.

In this study, we present nitrite determination via synthesis and characterisation of iron(III) monoamino-phthalocyanine (FeMAPc) followed by surface confinement onto a MPA/AuNPs modified glassy carbon electrode surface.

\section{Experimental}

\subsection{Materials}

3-Mercaptopropionic acid (MPA, 99\%), gold(III) chloride trihydrate $(>99.9 \%), N$-hydroxysuccinimide (NHS), $N$-(3-dimethylaminopropyl)- $N$-ethylcarbodiimide hydrochloride (EDC), sodium nitrite $(97 \%)$, sodium nitrate, potassium hexacyanoferrate(III) $(>99 \%)$, potassium hexacyanoferrate(II) trihydrate (>99.99\%), iron(III) chloride anhydrous, potassium phosphate monobasic (99\%) and potassium phosphate dibasic $(98 \%)$ were purchased from Sigma-Aldrich. 4-nitrophthalic anhydride and phthalic anhydride were purchased from Fluka. Phosphate buffer solution was prepared using $0.1 \mathrm{M} \mathrm{KH}_{2} \mathrm{PO}_{4}$ and $0.1 \mathrm{M} \mathrm{K}_{2} \mathrm{HPO}_{4}$.

\subsection{Apparatus and Measurements}

The surface morphology and distribution of the nanoparticles were characterised using scanning electron microscopy (JEOL JSM-6390LV model). For SEM/EDX measurements, samples were suspended in distilled water, sonicated and drop cast onto carbon tape fixed on $\mathrm{Al}$ sample stub and dried overnight. Elemental identification was achieved by EDX measurements. The presence of AuNPs was also confirmed by ultraviolet-visible absorption spectroscopy (BioTek Synergy H1-Hybrid detector).
FTIR analysis was performed using SHIMADZU IR Prestige-21 FTIR Spectrometer.

The electrochemical experiments (cyclic voltammetry, electrochemical impedance spectroscopy and differential pulse voltammetry measurements) were performed using an electrochemical workstation $\mathrm{CH}$ Instruments Inc. $750 \mathrm{~A}$, in acidic $\left(0.5 \mathrm{M} \mathrm{H}_{2} \mathrm{SO}_{4}\right)$ and phosphate buffer (0.1 M, pH 5.8) electrolytes, using a conventional threeelectrode cell $(5 \mathrm{~mL})$ at room temperature. A modified glassy carbon electrode ( $3 \mathrm{~mm}$ diameter) served as the working electrode, while platinum wire and a standard $\mathrm{Ag} / \mathrm{AgCl}$ electrode (filled with $3 \mathrm{M} \mathrm{KCl}$ ) were used as the counter and reference electrodes, respectively. Prior to electrochemical measurements, the glassy carbon electrode was polished with 1.0, 0.3, 0.05 micron size alumina powders, sonicated in acetone and distilled water, washed with deionised water and dried using argon at room temperature.

\subsection{Synthesis of Iron(III) Mononitro-Phthalocyanine and Iron(III) Monoamino-Phthalocyanine}

Iron(III) mononitro-phthalocyanine was synthesised by modifying the procedure reported for the synthesis of monocarboxy-phthalocyanine.[31] 4-Nitrophthalic anhydride (0.005 mole, $0.965 \mathrm{~g})$, phthalic anhydride (0.035 mole, $5.18 \mathrm{~g})$, iron(III) chloride anhydrous (0.01 mole, $1.622 \mathrm{~g})$, urea (25 g) and traces of ammonium molybdate tetrahydrate as a catalyst $(0.01 \mathrm{~g})$ were added to a round bottom flask containing $30 \mathrm{~mL}$ of nitrobenzene. The reaction mixture was refluxed $\left(200^{\circ} \mathrm{C}\right)$ with continuous stirring for $5 \mathrm{~h}$, until a stable dark blue color precipitate appeared. The solvent was discarded by filtration, followed by sufficient washing with $\mathrm{HCl}(1.0 \mathrm{M})$, $\mathrm{NaOH}(1.0 \mathrm{M})$ and distilled water until a colorless neutral filtrate was obtained. The precipitate obtained was expected to consist of a mixture of iron(III) phthalocyanine and Iron(III) mononitro-phthalocyanine.

In the next step, $1 \mathrm{~g}$ of the as-prepared iron phthalocyanine complexes, $5 \mathrm{~g}$ of sodium sulfide and $50 \mathrm{~mL}$ distilled water were added into a $250 \mathrm{~mL}$ round bottom flask.[32] The reaction mixture was heated at $50{ }^{\circ} \mathrm{C}$ with stirring for $5 \mathrm{~h}$, followed by filtration and washing of the precipitate with distilled water until a colorless filtrate was obtained. This resulted in reduction of the nitro substituted iron complex to the amino derivative (which was available for EDC/NHS attachment to the Au/SAM layer as described below). FTIR spectrum of FeMAPc is shown in Figure 1, Two weak absorption bands were observed at 3348 and $3213 \mathrm{~cm}^{-1}$ due to the asymmetric and symmetric stretching of the amino group. In addition, bands at $729 \mathrm{~cm}^{-1}$ $(\mathrm{Fe}-\mathrm{N}), \quad 1080-1118 \mathrm{~cm}^{-1} \quad(\mathrm{C}-\mathrm{N}), \quad 1419 \mathrm{~cm}^{-1}, 1469 \mathrm{~cm}^{-1}$, $1495 \mathrm{~cm}^{-1} \quad$ (aromatic $\left.\mathrm{C}=\mathrm{C}\right), 1608 \mathrm{~cm}^{-1} \quad(\mathrm{~N}-\mathrm{H}$ bending) and $3055 \mathrm{~cm}^{-1}$ (aromatic $\mathrm{C}-\mathrm{H}$ ) were observed.[33,34] The absorption peak at $1724 \mathrm{~cm}^{-1}$ could be attributed to $\mathrm{C}=\mathrm{N}$ or $\mathrm{N}-\mathrm{H}$ deformations.[35] 


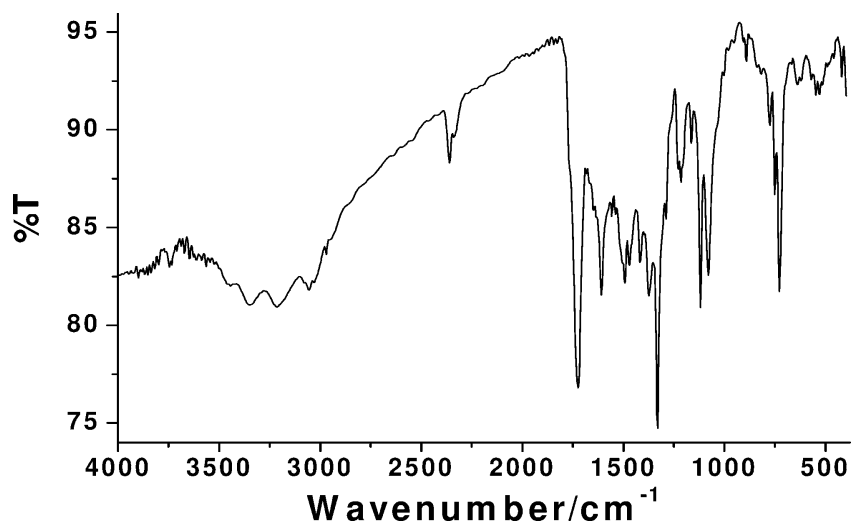

Fig. 1. IR spectrum of FeMAPc.

\subsection{Electrochemical Deposition of AuNPs on Surface of GCE}

A carefully cleaned glassy carbon electrode (GCE) was scanned between $0.0-1.6 \mathrm{~V}$ at $100 \mathrm{mV} / \mathrm{s}$ in a $0.5 \mathrm{M} \mathrm{H}_{2} \mathrm{SO}_{4}$ until a reproducible current response was obtained. The electrode was then immersed in a deaerated $(20 \mathrm{~min})$ solution of $2.5 \mathrm{mM} \mathrm{HAuCl} 4.3 \mathrm{H}_{2} \mathrm{O}$ in $0.1 \mathrm{M} \mathrm{NaNO}$ and scanned between $1.0-0.0 \mathrm{~V}$ at $50 \mathrm{mV} / \mathrm{s}$ for 10 cycles. This was followed by gentle washing of the electrode to remove any undeposited precursor ions. The so-obtained electrode was labelled as AuNPs/GCE.

\subsection{Immobilisation of FeMAPc via SAM Formation onto AuNPs/GCE}

The step by step schematic illustration of the electrode fabrication process is shown in Scheme 1. The AuNPs/ GCE was immersed overnight in an aqueous solution of 0.01 M MPA.[36] The electrode was then removed and washed gently with distilled water to remove any excess MPA. The activation of the terminal carboxylic group of the thiol linker [37] was achieved by immersing the MPA/ AuNPs/GCE in an ethanolic solution of $0.01 \mathrm{M} \mathrm{EDC/}$ $0.01 \mathrm{M}$ NHS for $2 \mathrm{~h}$. Finally, the covalent immobilisation of Iron(III) mononitro-phthalocyanine, was carried out by immersing the electrode in $0.001 \mathrm{M}$ of the catalyst in DMF for $3 \mathrm{~h}$. The electrode was then washed with DMF and distilled water to remove any weakly adsorbed material and dried at room temperature. The modified electrode is labelled as FeMAPc-MPA/AuNPs/GCE and employed in electrochemical measurements.

\section{Results and Discussion}

\subsection{Surface and Spectroscopic Characterisation}

SEM and EDX analysis together provide information regarding morphology, particle dispersion and elemental composition of the materials. SEM and EDX analysis of AuNPs and FeMAPc-MPA/AuNPs (following detachment from the electrode via sonication) are shown in Figure 2

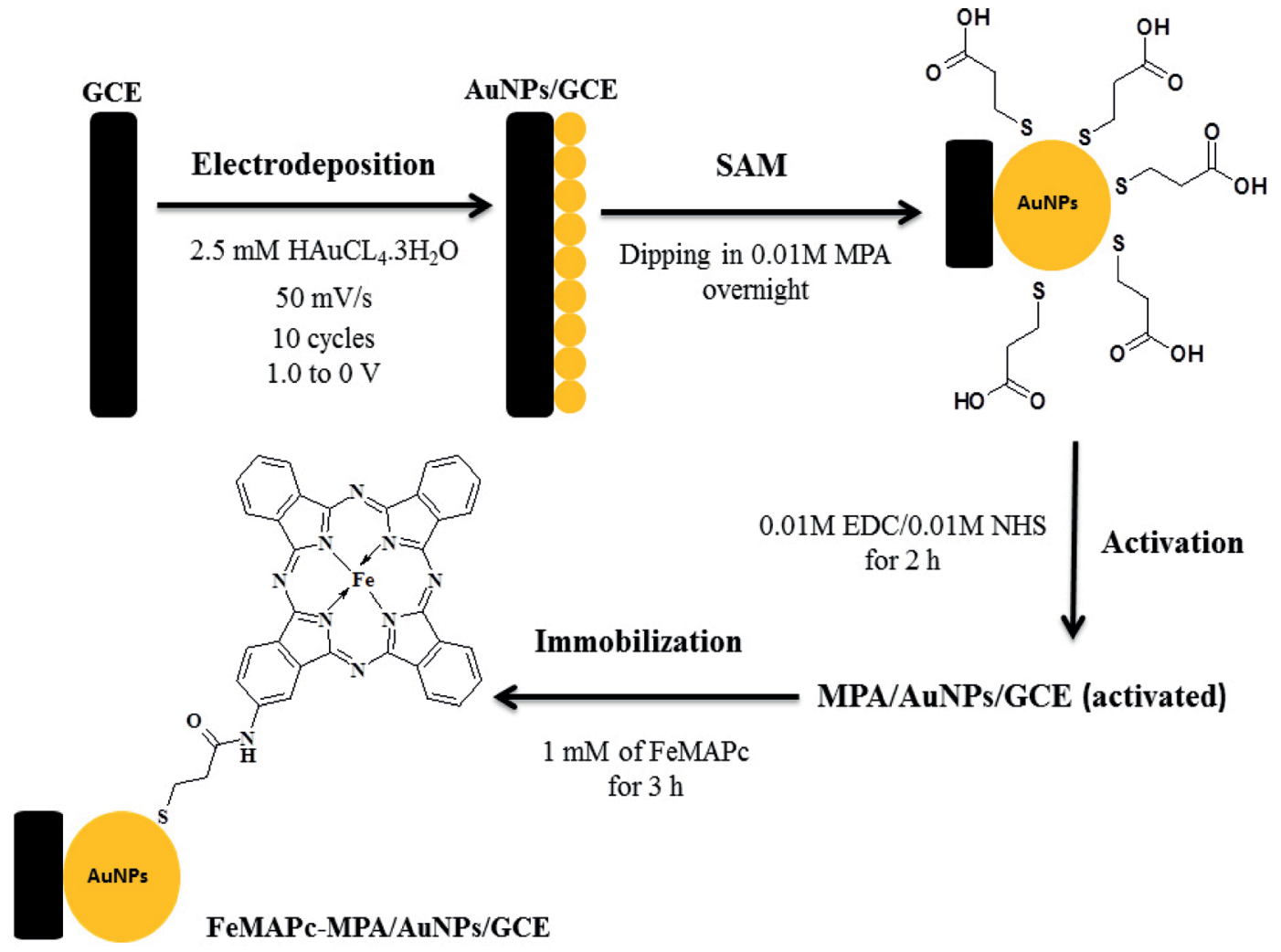

Scheme 1. Schematic illustration of the electrode preparation. 

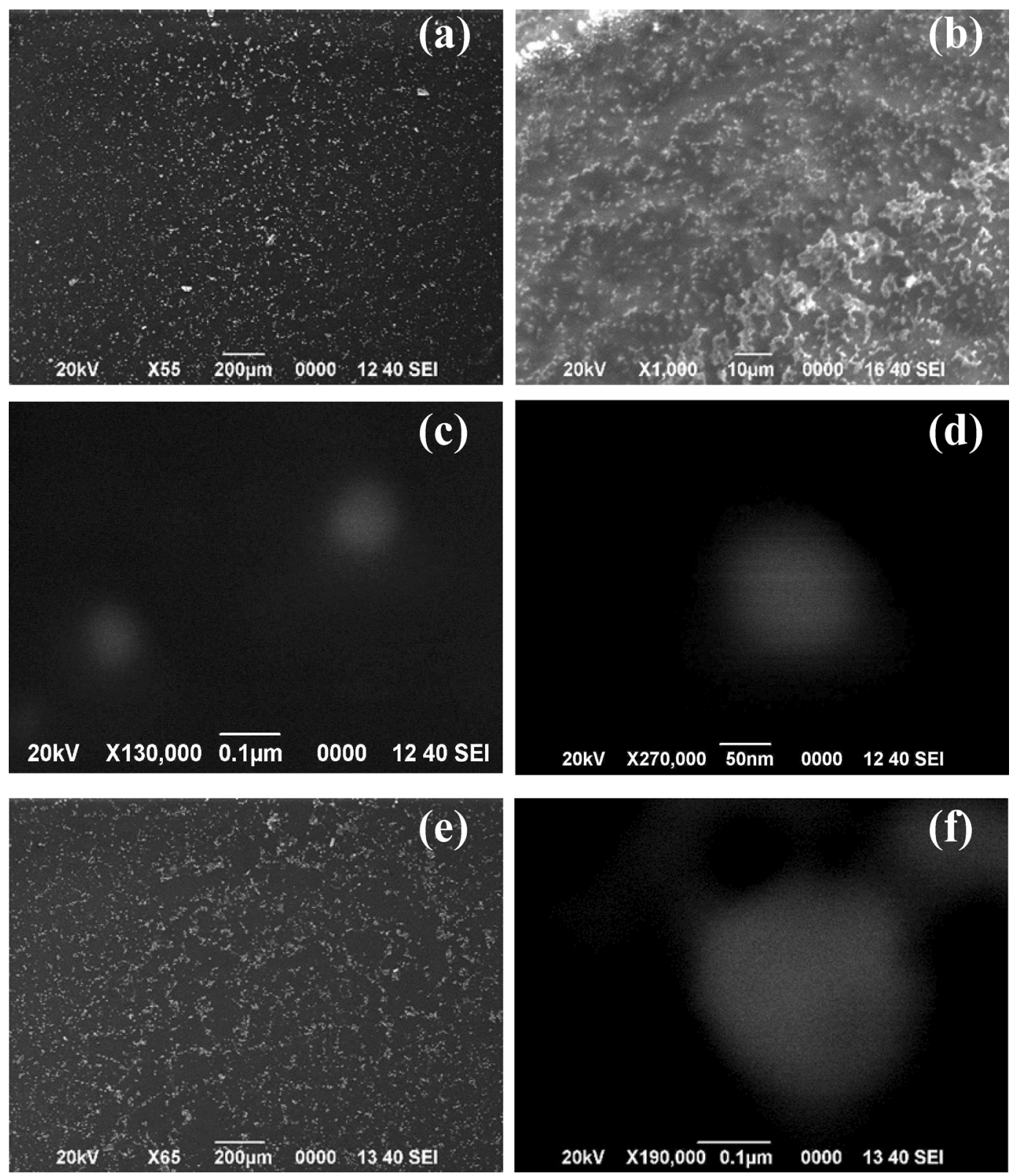

Fig. 2. SEM images of (a-d) AuNPs and (e,f) FeMAPc-MPA/AuNPs samples at different magnifications.

and Figure 3. SEM images confirm the dispersed nature of the nanoparticles and the high magnification images confirmed an approximate size of $100 \mathrm{~nm}$.

Elemental identification was confirmed via the EDX profiles (Figure 3 ) and was in agreement with the synthetic composition. The presence of carbon (C) signal is due to the carbon tape used for sample preparation for SEM analysis, the oxygen $(\mathrm{O})$ signal is due to the contribution from environmental oxygen, adsorbed water and from MPA (in case of FeMAPc-MPA/AuNPs). The presence of sulfur (S) signal is attributed to the sulfur atom of the MPA which also confirms the SAM formation (Au-S bond). The presence of Fe signals (Figure $3 \mathrm{~b}$ ), confirms the successful immobilisation of FeMAPc.
The electrode materials were also characterised using UV-visible spectroscopy $(300-800 \mathrm{~nm})$. For this purpose, four AuNPs and four FeMAPc-MPA/AuNPs modified glassy carbon electrodes were sonicated in $210 \mu \mathrm{L}$ deionised water followed by transfer of $200 \mu \mathrm{L}$ into microwells for UV-visible spectroscopy measurements. Figure 4 shows the spectra (labelled) for the blank (deionised water, curve a), FeMAPc (curve b), AuNPs (curve c) and FeMAPc-MPA/AuNPs (curve d). In the case of the AuNPs a surface plasmon absorption wave was observed at $550 \mathrm{~nm}$ (curve c). The broad nature of the absorption curve may be attributed to the particle size effect or possible aggregation of the particles. In the case of FeMAPc (curve b), an absorption wave at $730 \mathrm{~nm}$ (Q band) was attributed to the $\pi \rightarrow \pi^{*}$ electronic transition from the 

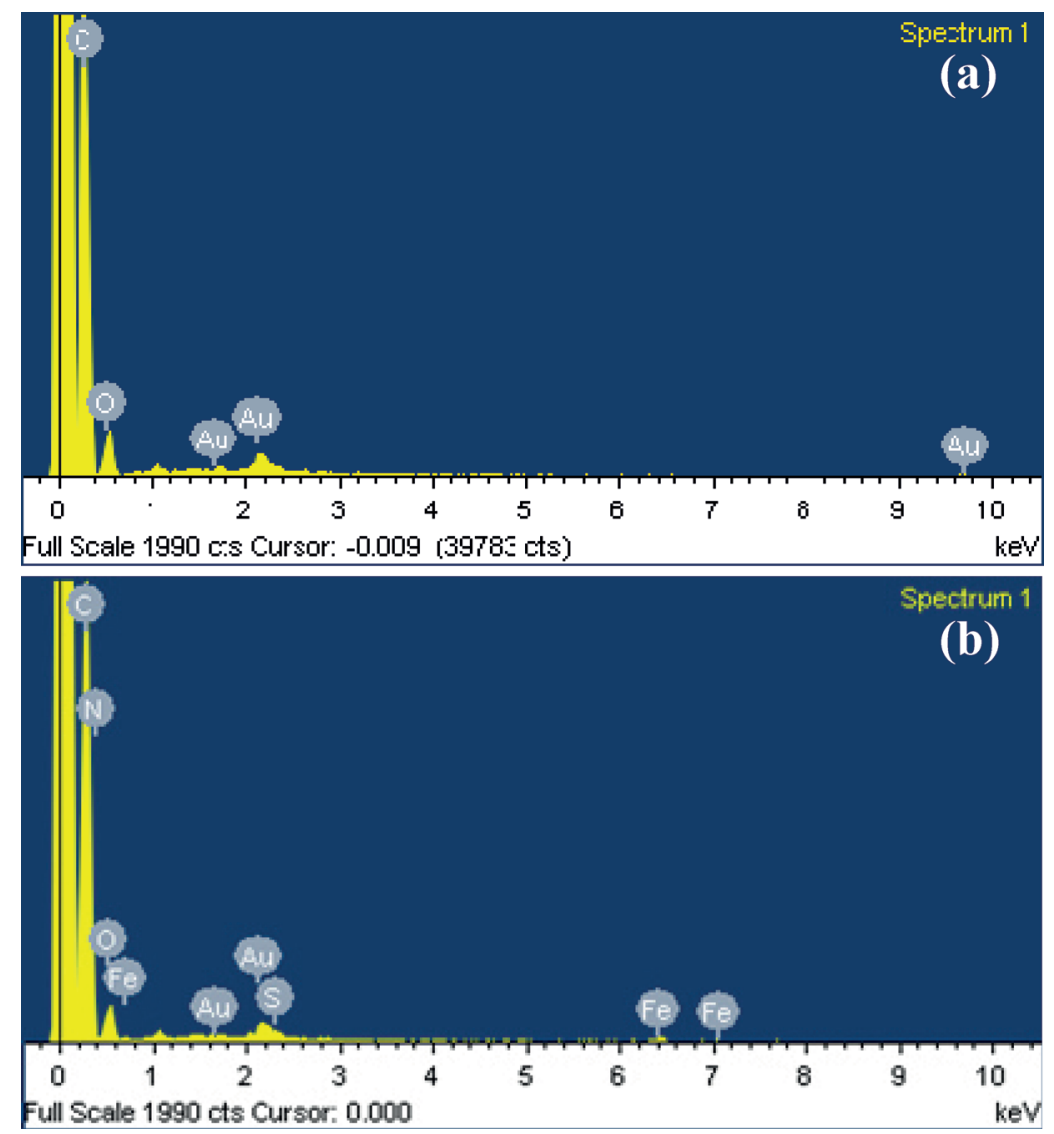

Fig. 3. EDX profiles of (a) AuNPs and (b) FeMAPc-MPA/AuNPs.

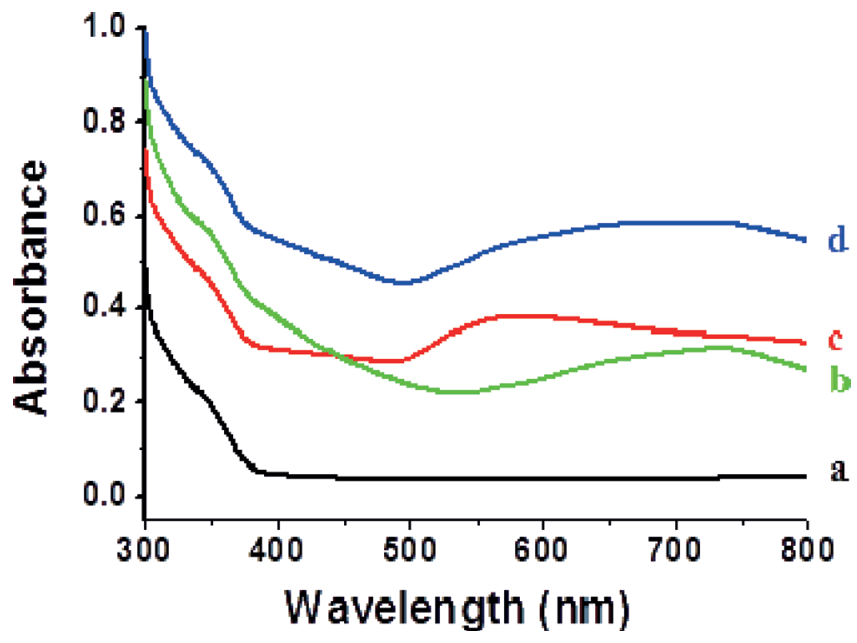

Fig. 4. UV-visible spectra of (a) blank (deionised water), (b) FeMAPc, (c) AuNPs and (d) FeMAPc-MPA/AuNPs.

HOMO (highest occupied molecular orbital) to the LUMO (lowest unoccupied molecular orbital) of the phthalocyanine ring.[38] A less intense band in the blue end of the UV region (B band) was observed at 400$450 \mathrm{~nm}$ and attributed to the deeper $\pi$ levels $\rightarrow$ LUMO transitions. The UV-visible spectra for FeMAPc-MPA/ AuNPs (curve d) showed a broad band from 550-750 nm, confirming the contribution from the AuNPs together with sucessful FeMAPc attachment.

\subsection{Electrochemical Characterisation - CV and EIS Measurements}

The cyclic voltammetric response during AuNPs electrodeposition is shown in Figure 5 A. The first and last cycles are labelled. At the first cycle $\mathrm{Au}(\mathrm{III})$ is reduced to $\mathrm{Au}(0)$ at $0.35 \mathrm{~V}$ and the formation of these nuclei induces the subsequent deposition of AuNPs on the GCE surface. The shift in peak position of the following cycles, from 0.35 to $0.7 \mathrm{~V}$ after ten cycles, confirms the $\mathrm{Au}$ depostion on the firstly formed $\mathrm{Au}$ nuclei. Following nanoparticle deposition, the electrode was washed gently in order to remove any precursor ions and labelled as AuNPs/GCE.

The various stages of electrode modification were characterised firstly by potential scanning in a redox couple, $5 \mathrm{mM}\left[\mathrm{Fe}(\mathrm{CN})_{6}\right]^{3-/ 4-}(1: 1)$, from 0.7 to $-0.2 \mathrm{~V}$ at a scan rate of $100 \mathrm{mV} / \mathrm{s}$. From Figure $5 \mathrm{~B}$, it was observed that the oxidation and reduction current peaks and $E_{\mathrm{p}}$ values were influenced during each step of electrode fabrication. AuNPs electrodeposition amplifies the current response (curve b) compared to bare GCE (curve a), due to the high surface-to-volume ratio of the nanoparticles. Assembly of a monolayer of MPA blocks the electron transfer process and this is revealed by the highest $\Delta E$ value and 

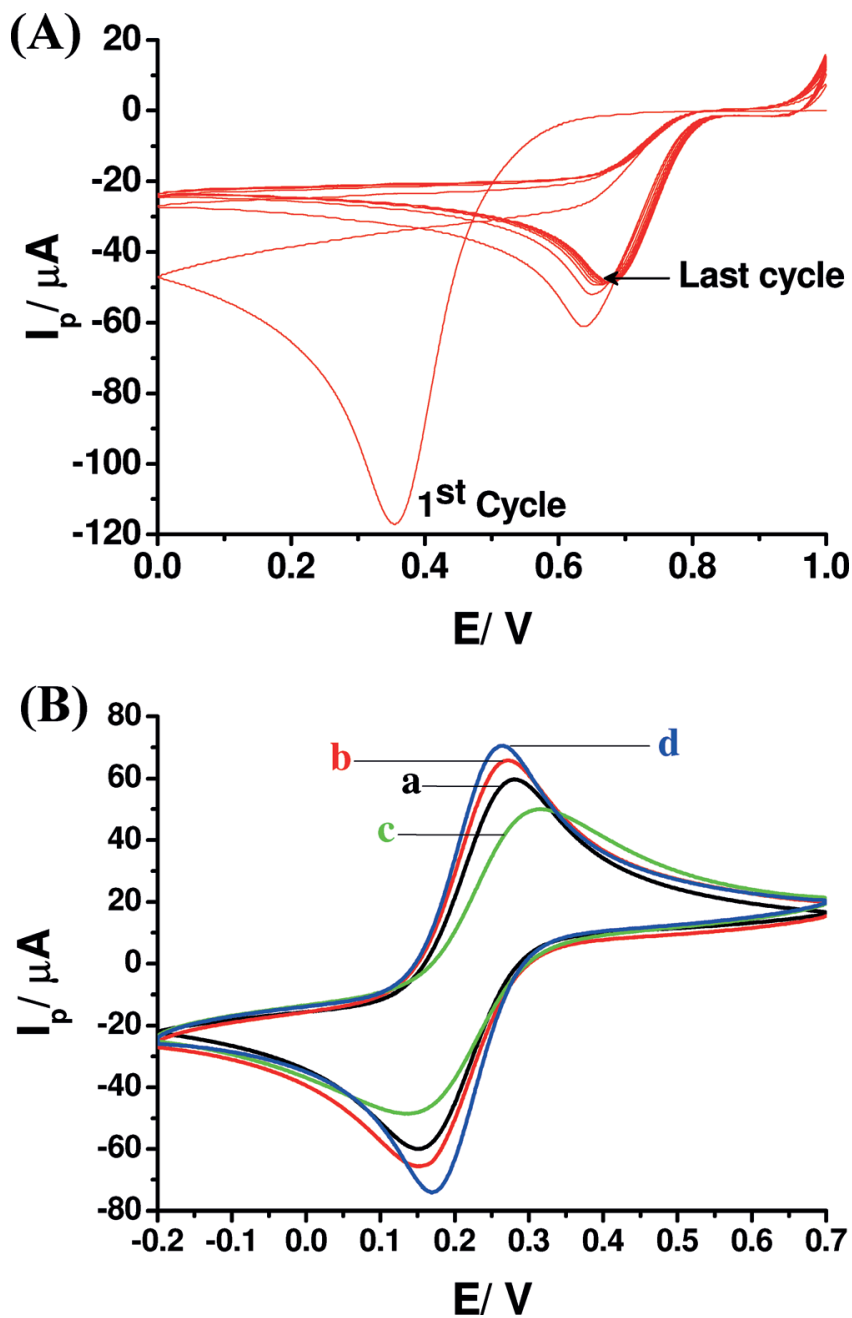

Fig. 5. (A) CV response recorded during AuNPs electrodeposition. (B) CVs of (a) bare/GCE, (b) AuNPs/GCE, (c) MPA/ AuNPs/GCE and (d) FeMAPc-MPA/AuNPs/GCE in a solution of $5 \mathrm{mM}\left[\mathrm{Fe}(\mathrm{CN})_{6}\right]^{3-14-}$ and $0.1 \mathrm{M} \mathrm{KCl}$.

the lowest oxidation and reduction peak currents (curve c) at this stage of electrode fabrication. The success of covalent immobilisation was also confirmed from this study. The lowest $\Delta E$ value and greatest oxidation/reduction currents were observed for FeMAPc-MPA/AuNPs/GCE (curve d) (see Table 1) demonstrating the synergistic effect of FeMAPc and AuNPs in the final stage of electrode fabrication.

Electrochemical impedance spectroscopy (EIS) is an effective characterisation technique for examining interfacial properties of modified electrodes. From the EIS

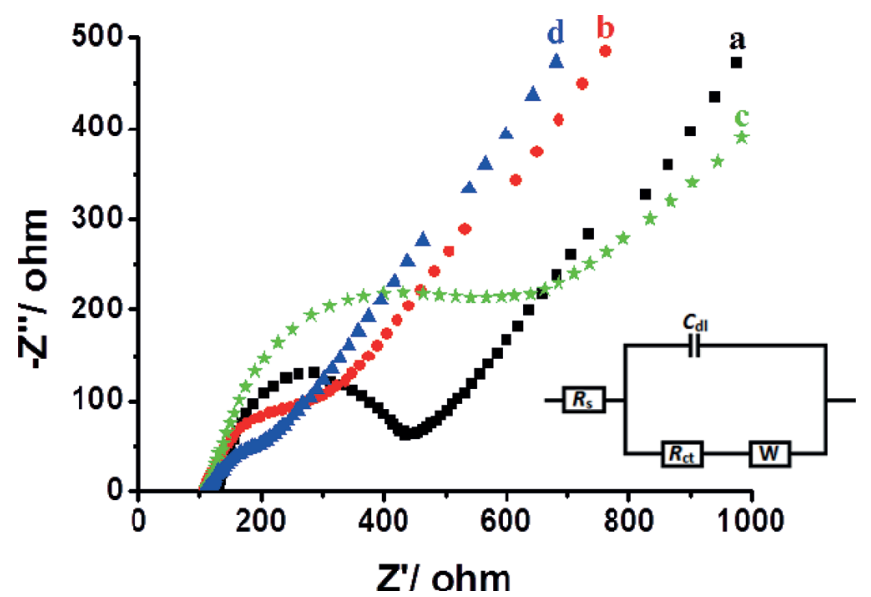

Fig. 6. EIS response of (a) bare/GCE, (b) AuNPs/GCE, (c) MPA/AuNPs/GCE and (d) FeMAPc-MPA/AuNPs/GCE in a solution of $5 \mathrm{mM}\left[\mathrm{Fe}(\mathrm{CN})_{6}\right]^{3-14-}$ and $0.1 \mathrm{M} \mathrm{KCl}$ at initial potential $0.22 \mathrm{~V}$ and from 0.1 to $10^{5} \mathrm{~Hz}$. Equivalent circuit used for $R_{\mathrm{ct}}$ calculations is shown as inset.

measurements (Figure 6, labelled) and equivalent electrical circuit designed from the impedance spectrum, $R_{\mathrm{ct}}$ values were calculated for each stage of electrode fabrication. The typical impedance spectrum, presented in the form of Nyquist plot, includes a semicircle at higher frequencies corresponding to the charge transfer limited process and a linear portion at lower frequency range representing the diffusion limited process.

The semicircle diameter in the impedance spectrum is a measure of the charge transfer resistance, $R_{\mathrm{ct}}$ and can be used to describe the interface properties at different stages of the electrode modification. Impedance data (Figure 6) was recorded from the Nyquist plot over the frequency range from 0.1 to $10^{5} \mathrm{~Hz}$ at initial potential $0.22 \mathrm{~V}$ and amplitude $5 \mathrm{mV}$ using $5 \mathrm{mM}\left[\mathrm{Fe}(\mathrm{CN})_{6}\right]^{3-/ 4-}$ $(1: 1)$ redox couple, at different electrode modification stages and was in agreement with the redox probe $\mathrm{CV}$ data above. Table 1 reveals that the electrodeposition of AuNPs decreased the electron resistance relative to the bare GCE and also proves that so formed MPA monolayer acts as a resistive layer due to the presence of negatively charged carboxylic groups which impede access of the anionic redox system. The electrode surface modified with the FeMAPc redox mediator resulted in a significant reduction in $R_{\mathrm{ct}}$ indicating electron transfer accessibility and utility of the so formed catalytic film. Standard heterogeneous rate constants were calculated and shown in Table 1 with the FeMAPc-MPA/AuNPs/GCE resulting in

Table 1. $\Delta E, I_{\mathrm{p}}, R_{\mathrm{ct}}$ and $k^{\circ}$ values of $\left[\mathrm{Fe}(\mathrm{CN})_{6}\right]^{3-/ 4-}$ redox couple.

\begin{tabular}{llllll}
\hline Electrode & $I_{\mathrm{a}}(\mu \mathrm{A})$ & $I_{\mathrm{c}}(\mu \mathrm{A})$ & $\Delta E(\mathrm{mV})$ & $R_{\mathrm{ct}}(\Omega)$ & 277.2 \\
\hline GCE & 67.43 & -64.62 & 128 & 133.6 & 0.00274 \\
AuNPs/GCE & 71.24 & -67.44 & 120 & 417.7 & 0.00569 \\
MPA/AuNPs/GCE & 50.58 & -46.8 & 178 & 64 & 0.00182 \\
FeMAPc-MPA/AuNPs/GCE & 76.71 & -79.68 & 96 & $\mathrm{~cm} / \mathrm{s})$ \\
\hline
\end{tabular}


a 10 fold increase in value relative to $k^{\circ}$ measured in the absence of the catalyst.

\subsection{Electrochemical Nitrite Detection Using FeMAPc- MPA/AuNPs Modified Glassy Carbon Electrode}

\subsubsection{Cyclic Voltammetry Measurements}

Surface redox characterisation was performed using CV in phosphate buffer solution and $\mathrm{H}_{2} \mathrm{SO}_{4}$ electrolytes. In $0.5 \mathrm{M} \mathrm{H}_{2} \mathrm{SO}_{4}$, no redox behaviour was evident for bare GCE (Figure 7 Aa) while AuNPs/GCE (Figure $7 \mathrm{Ab}$ ) showed the associated $\mathrm{Au}$ electrochemistry with a clear reduction wave observed at $c a$. $0.90 \mathrm{~V}$. Following self assembly of MPA (Figure 7 Ac), a decrease in the reduction current was observed which is attributed to the passivation of the AuNPs, though an increased oxidation wave was observed at $E_{\mathrm{p}}=1.09$ and $1.26 \mathrm{~V}$. This may be due to the oxidative desorption of MPA from AuNPs modified electrode surface [39]. Following FeMAPc immobilisation (Figure $7 \mathrm{Ad}$ ), the $\mathrm{Au}$ reduction current decreased with a slight anodic shift. In addition to the Au reduction wave $\left(E_{\mathrm{p}}=0.93 \mathrm{~V}\right)$, there was another peak observed at ca. $0.76 \mathrm{~V}$ which was attributed to reduction of $\mathrm{Fe}(\mathrm{III}) \mathrm{Pc}^{+}$to $\mathrm{Fe}(\mathrm{II}) \mathrm{Pc}$. An obvious increase in the oxidation peak of gold was recorded due to the overlap of the Fe(II)Pc iron oxidation at $1.0 \mathrm{~V}$ vs $\mathrm{Ag} / \mathrm{AgCl}$.

$\mathrm{NO}_{2}{ }^{-}$testing was performed using the FeMAPc-MPA/ AuNPs modified glassy carbon electrode in phosphate buffer solution (0.1 M, pH 5.8). $\mathrm{NO}_{2}{ }^{-}$in acidic solution is well known to be unstable and can undergo transformations to $\mathrm{NO}$ and $\mathrm{NO}_{3}{ }^{-}$, [40] but the oxidation of nitrite at higher $\mathrm{pH}$ values is difficult due to deficiency of protons [41]. Therefore, 0.1 M PBS pH 5.8 was selected for electrochemical nitrite detection studies. Figure $7 \mathrm{~B}$ shows the electrode response to $1 \mathrm{mM} \mathrm{NO}_{2}^{-}$in $0.1 \mathrm{M}$ PBS ( $\mathrm{pH} 5.8$ ) over the potential window $0.0-1.6 \mathrm{~V}$ at $50 \mathrm{mV} / \mathrm{s}$. The GCE showed a broad peak at around $1.13 \mathrm{~V}$ as labelled in Figure $7 \mathrm{Ba}$. When FeMAPc was directly drop cast onto the GCE surface (Figure 7Bb), the oxidation peak current of nitrite increased and shifted cathodically to $1.06 \mathrm{~V}$ which is an indication of the surface modification and the catalytic capability of FeMAPc. The AuNPs/GCE (Figure $7 \mathrm{Bc}$ ) resulted in a sharp peak at $0.81 \mathrm{~V}$, probably due to the high surface area offered by the nanoparticles for ease of access for the anion relative to the bare GCE. The FeMAPc-MPA/AuNPs modified glassy carbon electrode (Figure 7Bd), resulted in the highest current and lowest overpotential which was attributed to the combination of AuNPs and catalytic capability of FeMAPc.

The influence of scan rate was examined and Figure $8 \mathrm{~A}$ shows the voltammograms for the FeMAPcMPA/AuNPs modified glassy carbon electrode in $1 \mathrm{mM}$ $\mathrm{NO}_{2}^{-}$(0.1 M PBS, pH 5.8) at different scan rates (10$100 \mathrm{mV} / \mathrm{s})$. It was observed that the peak current increases $\left(I_{\mathrm{p}}\right)$ linearly with the square root of the scan rate $\left(v^{1 / 2}\right)$ (Figure 8B) which indicates that the oxidation of nitrite at FeMAPc-MPA/AuNPs/GCE was diffusion-controlled process.
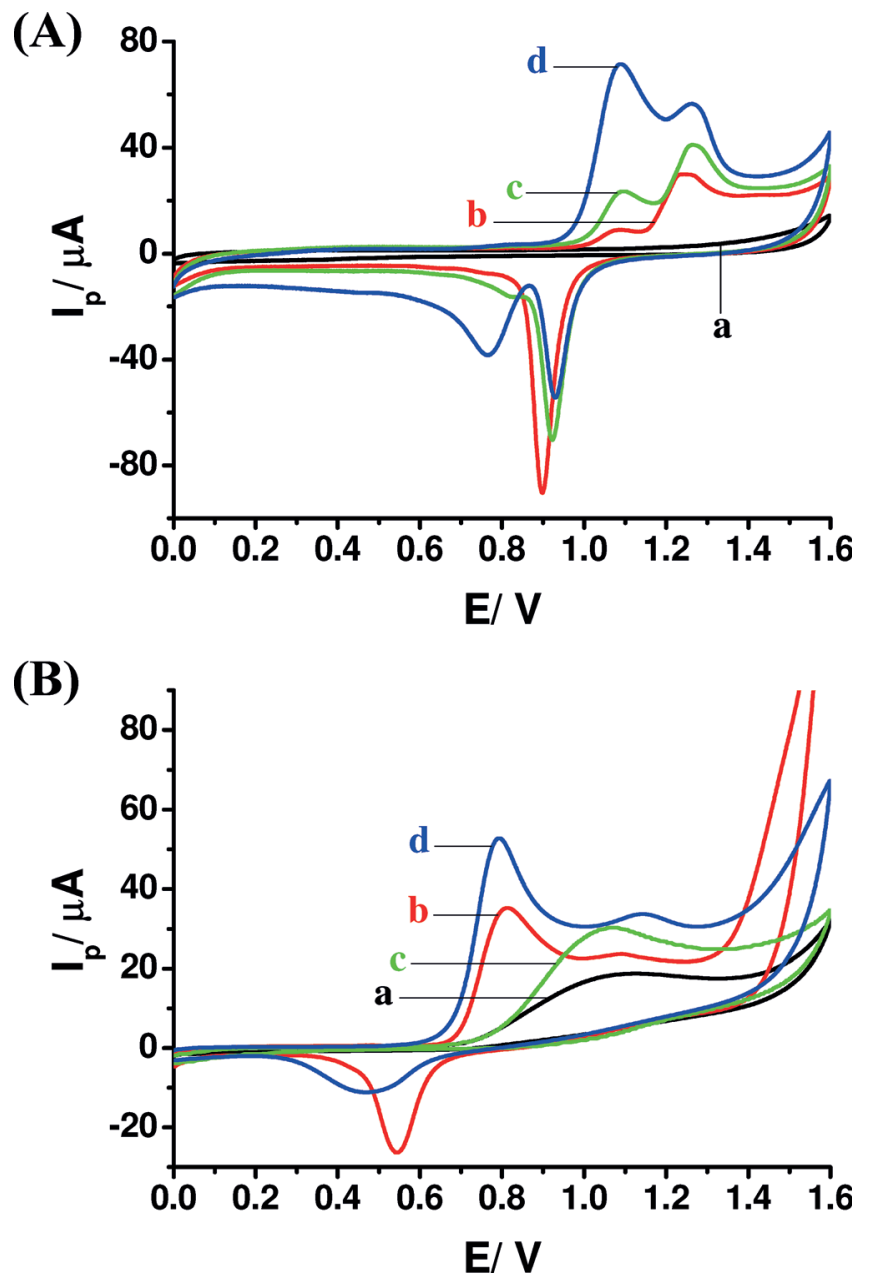

Fig. 7. (A) CVs recorded in $0.5 \mathrm{M} \mathrm{H}_{2} \mathrm{SO}_{4}$; (a) bare/GCE, (b) AuNPs/GCE, (c) MPA/AuNPs/GCE and (d) FeMAPc-MPA/ AuNPs/GCE. (B) CVs in $1 \mathrm{mM} \mathrm{NO}_{2}^{-}$(0.1 M PBS, pH 5.8); (a) bare/GCE, (b) AuNPs/GCE, (c) FeMAPc/GCE and (d) FeMAPc-MPA/AuNPs/GCE.

The peak potential $\left(E_{\mathrm{p}}\right)$ was plotted versus $\log v$ and resulted in a straight line $\left(y=0.0477 x+0.8519, \mathrm{R}^{2}=0.99\right)$, indicating the irreversibility of the nitrite oxidation process. The Tafel slope $(b)$, the electron transfer coefficient $(\alpha)$ and the number of the electron transfer involved in the rate-determining step $\left(n_{\alpha}\right)$ can be obtained from the equation applied for a totally irreversible diffusion-controlled process.[42]

$E_{\mathrm{p}}=(b / 2) \log v+$ constant

$E_{\mathrm{p}}=\left(2.3 R T / 2(1-\alpha) n_{\alpha} F\right) \log v+K$

The slope obtained indicates one-electron transfer to be the rate determining step [43,44], $(b=2 \times 47.7=$ $95.4 \mathrm{mV} /$ decade and $\alpha=0.38)$. A plot of $I_{\mathrm{p}} / v^{1 / 2}$ versus $v$, resulted in the typical shape of the $\mathrm{EC}^{\prime}$ catalytic process (data not shown).[45] Thus, the total number of electrons involved in the overall reaction $\left(n_{t}\right)$ can be determined from the following equation.[44] 
(A)
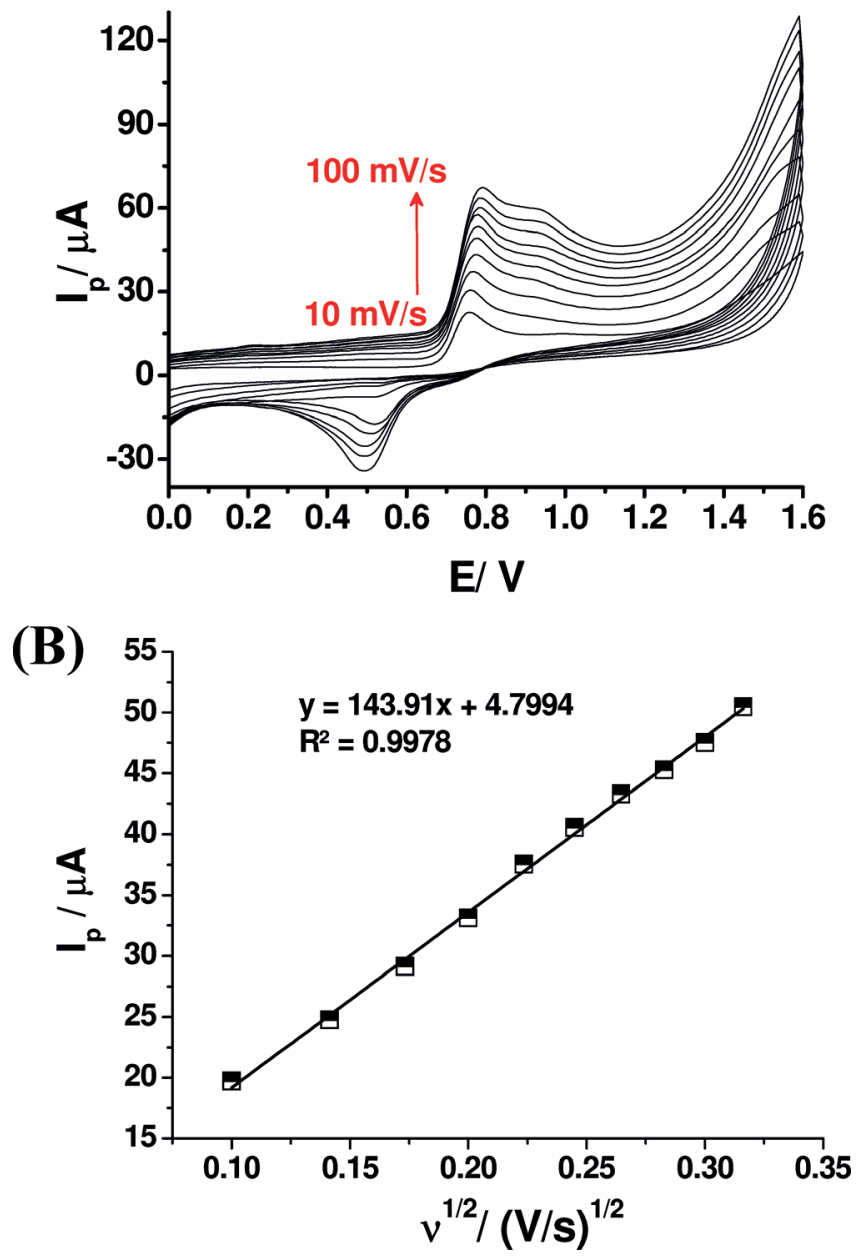

Fig. 8. (A) CVs recorded for FeMAPc-MPA/AuNPs/GCE in $1 \mathrm{mM} \mathrm{NO}_{2}{ }^{-}$in $0.1 \mathrm{M}$ PBS ( $\left.\mathrm{pH} 5.8\right)$ at different scan rates $(10$ $100 \mathrm{mV} / \mathrm{s})$. (B) Relationship between oxidation peak current $\left(I_{\mathrm{p}}\right)$ and square root of the scan rate $\left(v^{1 / 2}\right)$.

$$
I_{\mathrm{p}}=2.99 \times 10^{5} n_{t}\left[(1-\alpha) n_{\alpha}\right]^{1 / 2} A C D^{1 / 2} v^{1 / 2}
$$

Where $\quad I_{\mathrm{p}} / \nu^{1 / 2}=143.91 \mu \mathrm{A} /\left(\mathrm{V} \mathrm{s}^{-1}\right)^{1 / 2}, \quad(1-\alpha) n_{\alpha}=0.619$, $D=2.1 \times 10^{-5} \mathrm{~cm}^{2} \mathrm{~s}^{-1}$ [46], $A=0.07 \mathrm{~cm}^{2}, C=1 \times 10^{-6} \mathrm{~mol} /$ $\mathrm{cm}^{3}$. The value of $n_{t}$ was 1.9 , suggesting two electrons involved in the mechanism of nitrite oxidation, where nitrate is the predominant product of the reaction. The experimental data obtained is in agreement with the mechanisms proposed previously [47-49]. A chemical interaction firstly occurs between $\mathrm{NO}_{2}^{-}$and $\mathrm{Fe}(\mathrm{III}) \mathrm{Pc}^{+}$to form an adduct [43], followed by oxidation of this adduct, and then rapid disproportionation of $\mathrm{NO}_{2}[50]$.

$$
\begin{aligned}
& 2 \mathrm{Fe}(\mathrm{III}) \mathrm{Pc}^{+}+2 \mathrm{NO}_{2}{ }^{-} \rightarrow 2\left[\mathrm{Fe}(\mathrm{II}) \mathrm{Pc}-\mathrm{NO}_{2}\right] \\
& 2\left[\mathrm{Fe}(\mathrm{II}) \mathrm{Pc}_{-} \mathrm{NO}_{2}\right] \rightarrow 2 \mathrm{Fe}(\mathrm{III}) \mathrm{Pc}^{+}+2 \mathrm{NO}_{2}+2 \mathrm{e}^{-} \\
& 2 \mathrm{NO}_{2}+\mathrm{H}_{2} \mathrm{O} \rightarrow \mathrm{NO}_{2}{ }^{-}+\mathrm{NO}_{3}{ }^{-}+2 \mathrm{H}^{+}
\end{aligned}
$$

\subsubsection{Differential Pulse Voltammetry}

DPV measurements for different concentrations of $\mathrm{NO}_{2}{ }^{-}$ (Figure 9A) were recorded over the potential window (0.55-0.95 V in 0.1 M PBS ( $\mathrm{pH} 5.8)$ ), where both gold is active and $\mathrm{Fe}(\mathrm{II}) \mathrm{Pc}$ oxidation is possible. As the nitrite ions can also be oxidised within this potential window, the influence of both AuNPs and FeMAPc on the sensitivity of nitrite measurement was observed. Calibration curves corresponding to the various electrode modification stages are shown in Figure 9B. FeMAPc-MPA/ AuNPs/GCE showed the best response (sensitivity $14.5 \mathrm{nA} / \mu \mathrm{M}, R^{2}=0.9978$ ) while the calculated sensitivity values for AuNPs/GCE, FeMAPc/GCE and bare GCE were $7.6 \mathrm{nA} / \mu \mathrm{M} \quad\left(R^{2}=0.9933\right), 6.1 \mathrm{nA} / \mu \mathrm{M} \quad\left(R^{2}=0.9997\right)$ and $4.2 \mathrm{nA} / \mu \mathrm{M}\left(R^{2}=0.9964\right)$, respectively. The observed sensitivity response for FeMAPc-MPA/AuNPs/GCE was therefore 1.9 times the AuNPs/GCE, 2.4 times the FeMAPc/GCE and 3.5 times the bare GCE.
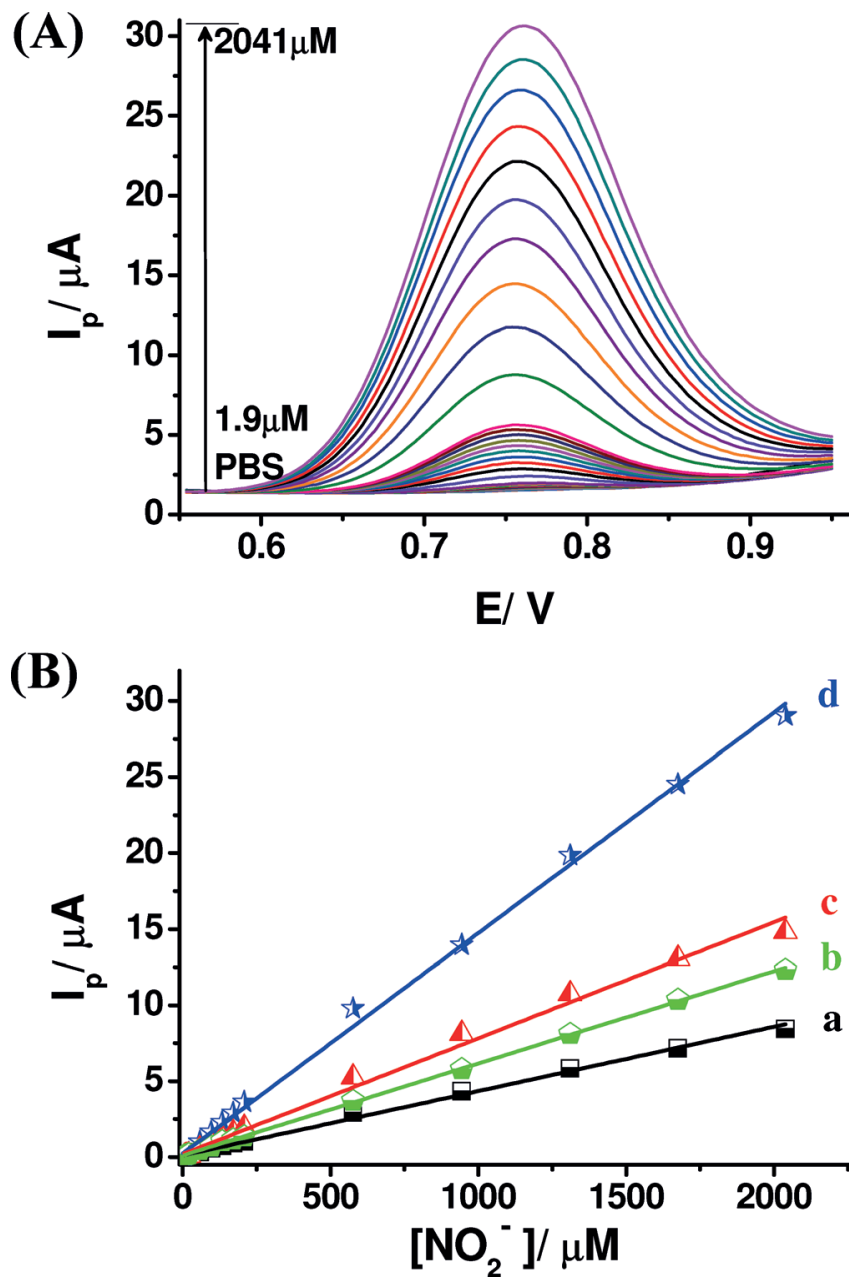

Fig. 9. (A) DPVs for FeMAPc-MPA/AuNPs/GCE in different concentrations of nitrite. (B) Calibration plot $\left(I_{\mathrm{p}}\right.$ vs. nitrite conc.) for different stages of electrode modification; (a) bare/GCE, (b) FeMAPc/GCE, (c) AuNPs/GCE and (d) FeMAPc-MPA/AuNPs/ GCE. 
This clearly demonstrated the role of AuNPs and FeMAPc in improving the surface characteristics of the proposed electrode for improved nitrite sensing. The different stages of electrode modification show a range of $E_{\mathrm{p}}$ values used to generate the calibration curve. These values were $0.91,0.94,0.77$ and $0.76 \mathrm{~V}$ for bare GCE, FeMAPc/GCE, AuNPs/GCE and FeMAPc-MPA/AuNPs/ GCE, respectively.

\subsection{Stability and Intra-Electrode Reproducibility Response}

The stability of FeMAPc-MPA/AuNPs modified glassy carbon electrode was tested in $0.1 \mathrm{M}$ PBS in the absence and presence of $100 \mu \mathrm{M}$ nitrite ion by continuous potential cycling (0.0-1.2 V, 25 cycles). A decrease in current response (at the nitrite oxidation peak $0.8 \mathrm{~V}$ vs. $\mathrm{Ag} / \mathrm{AgCl}$ ) of about $8.0 \%$ and $2.8 \%$ was observed during cycling in the absence and presence of $100 \mu \mathrm{M}$ nitrite ion, respectively. The stability of the proposed electrode was also evident from the cyclic voltammetric response in a $\left[\mathrm{Fe}(\mathrm{CN})_{6}\right]^{3-/ 4-}$ solution upon continuous potential cycling $(0.7$ to $-0.2 \mathrm{~V})$. A change of $2.5 \%$ in redox current response (oxidation peak current at $0.27 \mathrm{~V}$ ) was observed upon continuous cycling ( 25 cycles). All these studies demonstrate that the proposed electrode is capable of continuous and repetitive measurements with catalytic regeneration.

In order to ascertain the intra-electrode reproducibility, oxidation of $20 \mu \mathrm{M}$ nitrite ion in $0.1 \mathrm{M}$ PBS ( $\mathrm{pH}$ 5.8) was examined using a FeMAPc-MPA/AuNPs modified glassy carbon electrode, resulting in $\% R S D=11.3 \% \quad(n=18$, average $=316 \mathrm{nA}$ ), confirming a lack of surface fouling during operation. The stability of FeMAPc-MPA/AuNPs modified glassy carbon electrode was also examined over time at room temperature (dry state). The current response for the FeMAPc-MPA/AuNPs/GCE was recorded following 50 days $(n=12)$ and a signal decrease of approximately $3.0 \%$ was observed compared to the results firstly obtained upon calibration.

\subsection{Interference Study and Real Sample Analysis}

Possible interferences for the quantitative determination of nitrite on FeMAPc-MPA/AuNPs/GCE were investigated by addition of 100 fold excess of $\mathrm{Na}^{+}, \mathrm{K}^{+}, \mathrm{NH}_{4}{ }^{+}$, $\mathrm{Mg}^{2+}, \mathrm{Ca}^{2+}, \mathrm{CO}_{3}{ }^{2-}, \mathrm{HCO}_{3}{ }^{-}, \mathrm{NO}_{3}{ }^{-}, \mathrm{Cl}^{-}$, citrate, acetate and $\mathrm{SO}_{4}{ }^{2-}$ ions $\left(\mathrm{Na}_{2} \mathrm{CO}_{3}, \mathrm{NaHCO}_{3}, \mathrm{~K}_{2} \mathrm{SO}_{4}, \mathrm{KCl}, \mathrm{NaNO}_{3}\right.$, sodium citrate, sodium acetate, $\mathrm{CaCl}_{2}, \mathrm{MgCl}_{2}$ and $\mathrm{NH}_{4} \mathrm{Cl}$ ) in $0.1 \mathrm{M}$ PBS (containing $20 \mu \mathrm{M}$ nitrite). The \% change in the nitrite oxidation current response is shown as a bar

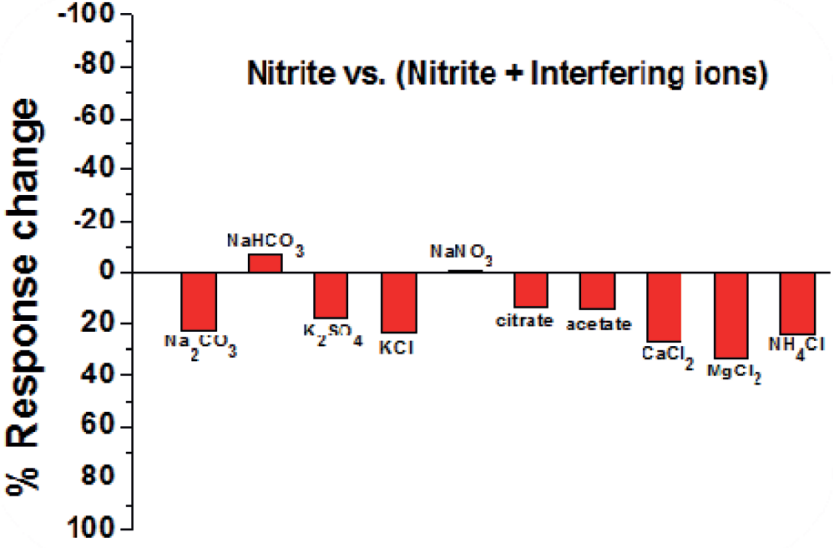

Fig. 10. Change in oxidation current ( $\%$ response change) for the determination of $20 \mu \mathrm{M}$ nitrite in the presence of 100 fold excess of interfering ions into $0.1 \mathrm{M} \mathrm{PBS}$ at FeMAPc-MPA/ AuNPs/GCE.

graph (Figure 10). The nitrite response was recorded before and after each interferent and compared as \% response change for each interferent. From the interference investigation, it was observed that only $\mathrm{HCO}_{3}^{-}$, $\left(\mathrm{NaHCO}_{3}\right)$ contributed to the nitrite response $(\sim 7 \%)$ while $\mathrm{NO}_{3}{ }^{-}$contributed less than $1 \%$. All other interferences did not show any increase in nitrite current response, but signal decreases were observed. This may have been due to either electrode insensitivity, chemical interaction or electrode fouling.

The modified electrode was also tested for nitrite detection using laboratory tap water (Table 2). The phosphate buffer solution was prepared with tap water and distilled water separately, and the results were compared. $25 \mu \mathrm{L}$ of $0.01 \mathrm{M}$ nitrite was added to $5 \mathrm{~mL}$ solution volume $(50 \mu \mathrm{M}$ nitrite) and measurements were recorded 5 times. A nitrite response of $59.44 \mu \mathrm{M}$ was found with a recovery $(99.6 \%)$ and relative standard deviation $(3.6 \%)$. Table 3 gives a comparison of similar reports in the recent literature providing evidence of the analytical benefits obtained via the use of this approach.

\section{Conclusions}

An electrochemical sensor (FeMAPc-MPA/AuNPs/GCE) was prepared and investigated for nitrite measurement using cyclic voltammetry and differential pulse voltammetry in phosphate buffer solution (0.1 M PBS, pH 5.8). The proposed sensor relied on the catalytic behaviour of the synthesised iron(III) monoamino-phthalocyanine catalyst for nitrite oxidation. SAM formation and catalyst attach-

Table 2. The determination of nitrite in laboratory tap water.

\begin{tabular}{llllll}
\hline Sample & Added $(\mu \mathrm{M})$ & Expected $(\mu \mathrm{M})$ & Found $(\mu \mathrm{M})$ & $R S D(\%, n=5)$ & Recovery $(\%, n=5)$ \\
\hline Lab. tap water & - & - & 9.66 & 4.2 & - \\
& 50 & 59.66 & 59.44 & 3.6 & 99.6 \\
\hline
\end{tabular}


Table 3. Comparison of this work with prior reports of nitrite detection.

\begin{tabular}{llll}
\hline Electrode material & Linear range & LOD $(\mu \mathrm{M})$ & Reference \\
\hline $\mathrm{Fe}(\mathrm{III}) \mathrm{P} / \mathrm{MWCNTs} / \mathrm{GCE}$ & $1-600 \mu \mathrm{M}$ & 0.5 & {$[51]$} \\
$\mathrm{SiO}_{2} @ \mathrm{Fe}_{3} \mathrm{O}_{4}$ & $0.72-110 \mu \mathrm{M}$ & 0.74 & {$[52]$} \\
$\mathrm{Au}-\mathrm{Pt}$ nanoparticles & $70 \mu \mathrm{M}-1.2 \mathrm{mM}$ & 2 & {$[53]$} \\
$\mathrm{Au}-\mathrm{Pt}$ nanoparticles & $2.5-400 \mu \mathrm{M}$ & 1 & {$[54]$} \\
$\mathrm{POA}$ & $2-50 \mu \mathrm{M}$ & 1.05 & {$[55]$} \\
$\mathrm{Fe}-\mathrm{HNPs}$ & $9 \mu \mathrm{M}-3 \mathrm{mM}$ & 2.6 & {$[56]$} \\
$\mathrm{Cu}-\mathrm{NDs} / \mathrm{rGO}$ & $1.25 \mu \mathrm{M}-13 \mathrm{mM}$ & 0.4 & {$[57]$} \\
$\mathrm{Fe}(\mathrm{bpy})_{3}^{2+} / \mathrm{Nf} / \mathrm{GCE}$ & $200 \mu \mathrm{M}-20 \mathrm{mM}$ & 30 & {$[58]$} \\
$\mathrm{FeMAPc-MPA} /$ AuNPs/GCE & $1.9 \mu \mathrm{M}-2 \mathrm{mM}$ & 0.21 & This work \\
\hline
\end{tabular}

ment is a simple, reproducible process with high durability as an analytical device. The first such use of this specific catalyst and its surface confinement results in improved surface characteristics and analytical performance relative to previous reports (linearity and $L O D$ ). Data generated demonstrate the significant role of gold nanoparticles and the catalytic capabilities of FeMAPc-AuNPs combination in improving the electro-catalytic nitrite response at $E_{\mathrm{p}}=$ $0.75 \mathrm{~V}$ vs. $\mathrm{Ag} / \mathrm{AgCl}$ with evidence of operation in spiked water samples.

\section{Acknowledgements}

The authors acknowledge EU FP7 - Marie Curie IRSES (SmartCancerSens) funding and NATO Science for Peace Project "Novel Electrochmical Nano-Sensors for Toxic Ions Detection" CBP.NUKR.SFP 984173.

\section{References}

[1] A. Alonso, B. Etxaniz, M. D. Martinez, Food Addit. Contam.1992, 9, 111-117.

[2] N. Sparata, T. N. Rao, D. A. Tryk, A. Fujishima, J. Electrochem. Soc. 2001, 148, E112-E117.

[3] S. S. Mirvish, Cancer Lett. 1995, 93, 17-48.

[4] C. K. Chow, C. B. Hong, Toxicology 2002, 180, 195-207.

[5] I. A. Wolf, A. E. Wasserman, Science 1972, 177, 15-19.

[6] Guidelines for Drinking-Water Quality, Vol.1, 3rd ed., WHO, Geneva, 2004.

[7] H. Chen, C. Mousty, S. Cosnier, C. Silveira, J. J. G. Moura, M. G. Almeida, Electrochem. Commun. 2007, 9, 2240-2245.

[8] V. Vishnuvardhan, R. Kala, T. P. Rao, Anal. Chim. Acta 2008, 623, 53-58.

[9] M. N. Abbas, G. A. Mostafa, Anal. Chim. Acta 2000, 410, $185-192$.

[10] I. M. P. L. V. O. Ferreira, S. Silva, Talanta 2008, 74, 1598 1602.

[11] H. Zhang, L. Zhang, C. Lu, L. Zhao, Z. Zheng, Spectrochim. Acta, Part A, Mol. Biomol. Spectrosc. 2012, 85, $217-$ 222.

[12] É. Szökő, T. Tábi, A. S. Halász, M. Pálfi, K. Magyar, J. Chromatogr. A 2004, 1051, 177-183.

[13] H. Wang, W. Yang, S.-C. Liang, Z.-M. Zhang, H.-S. Zhang, Anal. Chim. Acta 2000, 419, 169-173.

[14] A. I. Gopalan, K.-P. Lee, S. Komathi, Biosens. Bioelectron. 2010, 26, 1638-1643.

[15] Y. Wang, J. Qu, R. Wu, P. Lei, Water Res. 2006, 40, 1224 1232.
[16] M. A. Kamyabi, F. Aghajanloo, J. Electroanal. Chem. 2008, 614, 157-165.

[17] M. R. Ganjali, S. Shirvani-Arani, P. Norouzi, M. Rezapour, M. Salavati-Niasari, Microchim. Acta 2004, 146, 35-41.

[18] A. L. Sousa, W. J. R. Santos, R. C. S. Luz, F. S. Damos, L. T. Kubota, A. A. Tanaka, S. M. C. N. Tanaka, Talanta 2008, 75, $333-338$

[19] J. E. Newbery, M. P. L. Haddad, Analyst 1985, 110, 81-82.

[20] M. Biesaga, K. Pyrzyńska, M. Trozanowicz, Talanta 2000, $51,209-224$

[21] J. H. Zagal, S. Griveau, J. F. Silva, T. Nyokong, F. Bedioui, Coord. Chem. Rev. 2010, 254, 2755-2791.

[22] J. H. Zagal, Coord. Chem. Rev. 1992, 119, 89-136.

[23] N. Chebotareva, T. Nyokong, J. Appl. Electrochem. 1997, 27, 975-981.

[24] D. Y. Hwang, J. Park, S. Kim, Bull. Korean Chem. Soc. 1998, 19, 795-797.

[25] S. Wang, Y. Yin, X. Lin, Electrochem. Commun. 2004, 6, 259-262.

[26] A. Maringa, E. Antunes, T. Nyokong, Electrochim. Acta 2014, 121, 93-101.

[27] W. S. Cardoso, Y. Gushikem, J. Electroanal. Chem. 2005, $583,300-306$.

[28] A. Ulman, Chem. Rev. 1996, 96, 1533-1554.

[29] T. Sagara, N. Kato, N. Nakashima, J. Phys. Chem. B 2002, 106, 1205-1212.

[30] M. Yang, Z. Zhang, Electrochim. Acta 2004, 49, 5089-5095.

[31] J. Chen, N. Chen, J. Huang, J. Wang, M. Huang, Inorg. Chem. Commun. 2006, 9, 313-315.

[32] B. N. Achar, G. M. Fohlen, J. A. Parker, J. Keshavayya, Polyhedron 1987, 6, 1463-1467.

[33] O. Adegoke, T. Nyokong, Synth. Metals 2014, 188, 35-45.

[34] T. M. Mohan Kumar, B. N. Achar, J. Organometallic Chem. 2006, 691, 331-336.

[35] T. Mugadza, T. Nyokong, Electrochim. Acta 2010, 55, 26062613.

[36] P. Kar, F. Tatard, G. Lamblin, P. Banet, P. H. Aubert, C. Plesse, C. Chevrot, J. Electroanal. Chem. 2013, 692, 17-25.

[37] C. A. G. N. Montalbetti, V. Falque, Tetrahedron 2005, 61, 10827-10852.

[38] A. B. P. Lever, Adv. Inorg. Chem. Radiochem 1965, 7, $27-$ 114.

[39] S.-F. Liu, X.-H. Li, Y.-C. Li, Y.-F. Li, J.-R. Li, L. Jiang, Electrochim. Acta 2005, 51, 427-431.

[40] O. Brylev, M. Sarrazin, L. Roue, D. Belanger, Electrochim. Acta 2007, 52, 6237-6247.

[41] W. Sun, S. Zhang, H. Liu, L. Jin, J. Kong, Anal. Chim. Acta 1999, 388, 103-110.

[42] B. Agboola, T. Nyokong, Anal. Chim. Acta 2007, 587, 116123. 
[43] M. H. Pournaghi-Azar, H. Dastangoo, J. Electroanal. Chem. 2004, 567, 211-218.

[44] A. J. Bard, L. R. Faulker, Electrochemical Methods, 2nd ed., Wiley, New York, 2001.

[45] F. Pariente, E. Lorenzo, F. Tobalina, H. D. Abruna, Anal. Chem. 1995, 67, 3936-3944.

[46] W. J. R. Santos, A. L. Sousa, R. C. S. Luz, F. S. Damos, L. T. Kubota, A. A. Tanaka, S. M. C. N. Tanaka, Talanta 2006, 70, $588-594$

[47] C.-Y. Lin, A. Balamurugan, Y.-H. Lai, K.-C. Ho, Talanta 2010, 82, 1905-1911.

[48] C. A. Caro, F. Bedioui, M. A. Páez, G. I. Cárdenas-Jiron, J. H. Zagal, J. Electrochem. Soc. 2004, 151, E32-E39.

[49] F. Matemadombo, T. Nyokong, Electrochim. Acta 2007, 52, $6856-6864$.

[50] R. Guidelli, Anal. Chem. 1972, 44, 745-755.

[51] C. Wang, R. Yuan, Y. Q. Chai, S. H. Chen, Y. Zhang, F. X. Hu, M. H. Zhang, Electrochim. Acta 2012, 62, 109-115.
[52] A. Afkhami, T. Madrakian, H. Ghaedi, H. Khanmohammadi, Electrochim. Acta 2012, 66, 255-264.

[53] Y. Zhang, R. Yuan, Y. Chai, J. Wang, H. Zhong, J. Chem. Technol. Biotechnol. 2012, 87, 570-574.

[54] Y. Song, Y. Ma, Y. Wang, J. Di, Y. Tu, Electrochim. Acta 2010, 55, 4909-4914.

[55] R. Ojani, J.-B. Raoof, S. Zamani, Appl. Surf. Sci. 2013, 271, 98-104.

[56] C. Xia, X. Yanjun, W. Ning, Electrochim. Acta 2012, 59, 8185.

[57] D. Zhang, Y. Fang, Z. Miao, M. Ma, X. Du, S. Takahashi, J. Anzai, Q. Chen, Electrochim. Acta 2013, 107, 656-663.

[58] U. P. Azad, V. Ganesan, Chem. Commun. 2010, 46, 61566158.

Received: October 8, 2014 Accepted: November 25, 2014 Published online: February 20, 2015 